\title{
Qualitative and quantitative approaches of occupational risks agents in a Brazilian facility
}

\author{
J. C. G. G. Carneiro; A. S. Alves; D. L. Rodrigues; D. S. Levy and \\ G. M. A. A. Sordi \\ Instituto de Pesquisas Energéticas e Nucleares (IPEN/CNEN-SP), \\ 05508-000, São Paulo-SP, Brasil \\ janetegc@ipen.br
}

\begin{abstract}
The occupational risk assessment is a structured and systematic process, which depends on the correct identification of probable risk factors and agents potentially found at workplace. The objective of this paper was to carry out the basic characterization of a Brazilian radioisotope production facility through ample knowledge of the workplace, workforce, performed tasks and identification and evaluation of occupational risk agents at the workplace. The data analyses comprised qualitative or quantitative approaches based on subjective information obtained by questionnaire, interviews and observations about workplace, workforce and risk agents. The workforce was distributed into eight work processes. Regarding task-related exposure there was assumed that all workers presented the same expo- sure profile. Therefore, an evaluation of the association degree between the occupational risk agents was undertaken; 17 risk agents were identified at the workplace, including physical, chemical, biological, ergonomic and accident risks. Although the workers may be potentially exposed to different risk agents, the ionizing radiation was the main physical risk factor observed in this facility.
\end{abstract}

Keywords: occupational exposure, risk agents, ionizing radiation 


\section{INTRODUCTION}

The use of radioisotopes in medicine is one of the most important social applications of Nuclear Energy, and the Nuclear and Energy Research Institute (IPEN), in São Paulo, is a national leader institution in research and development in the radiopharmaceutical area.

Currently, there are more than 30 products available for medical uses listed in the IPEN catalogue for products and services. The production of IPEN Radiopharmaceuticals Center is divided in 3 different areas: Radioisotopes $\left({ }^{99 \mathrm{~m}} \mathrm{Tc}\right.$ generators and Primary Radioisotopes as $\left.{ }^{131} \mathrm{I}\right)$, Labeled Compounds $\left({ }^{131} \mathrm{I}\right.$ and $\left.{ }^{18} \mathrm{~F}\right)$ for diagnosis (PET and SPECT) and Therapy and Lyophilized Kits for labeling with ${ }^{99 \mathrm{~m}} \mathrm{Tc}$.

IPEN has a rigorous program of radiological control for the radiological safety of workers and general public, through radiation protection programs in full compliance with national and international standards [1-3].

The work process of the occupationally exposed individuals, OEIs, in the production of radioisotopes and radiopharmaceuticals, includes singularities that do not exist in other categories of processes, such as exposure to physical risk agents (ionizing radiation, presence of noise, among others), chemical risk agents (chemical products as ammonium acetate; solvents - chloroform and flammable substances - methanol), biological risk agents (objects contaminated by bacteria), accidents (fire) and ergonomic issues [4]. This study is focused particularly on the exposure to ionizing radiation as a risk agent, since it is a radioactive facility where the exposure to ionizing radiation is inevitable.

The main purpose of this paper was to carry out the basic characterization of the facility through ample knowledge of the workplace, workforce, performed tasks and identification and evaluation of occupational risk agents in the workplace. 


\section{METHOD AND MATERIALS}

\subsection{Sampling and data analysis}

This Brazilian radiopharmaceutical facility is composed by 204 workers: 102 federal public employees (50\%), 57 hired employees (27.94\%) and 45 students / trainees (22.06\%). This study was limited to public employees, which represented $50 \%$ of total facility population. The data were collected from April 2013 to July 2014, applying questionnaires, interviews and direct observations. The respondents of the questionnaire were the managers of each workgroup at the facility. The structured questionnaire, with thirty-one questions collected information on work involving materials used in the research and production of new radiopharmaceuticals, workplace conditions, individual and collective protection equipment and identification of provable risk agents related to the worker tasks $[4,5]$.

The development of this study comprised a detailed evaluation process, covering a basic characterization of the workplace, workgroups and the identification of the probable occupational risks of the workers due to the execution of their tasks. Quantitative and qualitative approaches have been selected because of the need to integrate numerical data to the subjective questions in an attempt to complement the data.

The following software applications were used in this study: Statistical Package for Social Science (SPSS) version 17, Minitab 16 and Microsoft Excel 2010. Initially, qualitative and quantitative variables were studied through descriptive statistics, considering the frequency and distribution of a particular event $[6,7]$.

\subsection{Radiological control from 2013 to 2014}

The radiological control of the facility usually requires the use of various techniques for determining the radiological parameters, associated to air contamination, surface contamination, individual and environmental monitoring. In general, it is desired to use the monitoring techniques which have advantages in terms of time, cost or easiness of handling while at the same time are sensitive enough [1-3, 8, 9].

The procedures for area monitoring to detect external radiation in the workplace involve necessarily 
occupational monitoring and task-related monitoring. For the radiological control, the following monitors were used:

- 18 points continuously monitored by fixed Geiger Mueller detectors

- 11 points monitored by thermoluminescent dosimeters, TLD (CaSo 4 :Dy), located in selected areas, with trimestral sampling frequency.

The surface contamination was assessed by indirect methods, using a smearing test followed by high-resolution gamma-ray spectrometry.

Indirect methods and high purity germanium semiconductor detectors were used for indoor air monitoring. The portable air samplers were located at workplaces where there was a probability of air contamination.

The data analyses of the individual monitoring (TLD and in vivo measurements) were obtained through the consultation of the historical dose reports.

The environmental radiological control outdoors was established according to the Environmental Radiological Monitoring Program of IPEN, PMRA 2013 [8]. TL dosimeters, with a quarterly frequency were used for environmental monitoring. Moreover, air samples at the parking lot collected information about gamma emitters radionuclides, which were analyzed using filter paper and Activated Carbon Cartridge.

\section{RESULTS AND DISCUSSIONS}

\subsection{Basic characterization - evaluation of occupational exposure}

Based on the subjective information obtained by application of the questionnaire, the 102 responders have been distributed into eight work processes: Production of primary radioisotopes (26\%), Labeled compounds with ${ }^{131} \mathrm{I}$ and ${ }^{18} \mathrm{~F}(8 \%)$, Lyophilized kits for labeling with ${ }^{99 \mathrm{~m}} \mathrm{Tc},(2 \%)$, Quality control (23\%), Quality assurance (4\%), Research, Development and Innovation (5\%), Infrastructure and Support (25\%) and Radiation protection team (7\%).

\subsubsection{Worker profile - analysis of sociodemographic variables}

Statistical test for the equality of two proportions was used to determine the distribution of the 
relative frequency of socio-demographic variables, such as gender, educational level and age of workers. The results of the distribution related to the gender showed a predominantly male- gender population $(74.5 \%)$ of the total respondents. The educational level variable showed that the technical level was the majority of the sample $(70.6 \%)$ and the average age of workers was about $(51.8 \pm 1.7)$ years.

\subsection{Qualitative and quantitative assessment of occupational risk}

Through the subjective information collected through the questionnaire, it was possible to per- form the qualitative assessment by the basic characterization of the workplace, workgroups and performed tasks $[4,5]$.

Seventeen risk agents at workplace have been identified, as well as their frequencies in the eight work processes, as seen in Figure 1.

Figure 1: Identification of risk agents related to work processes

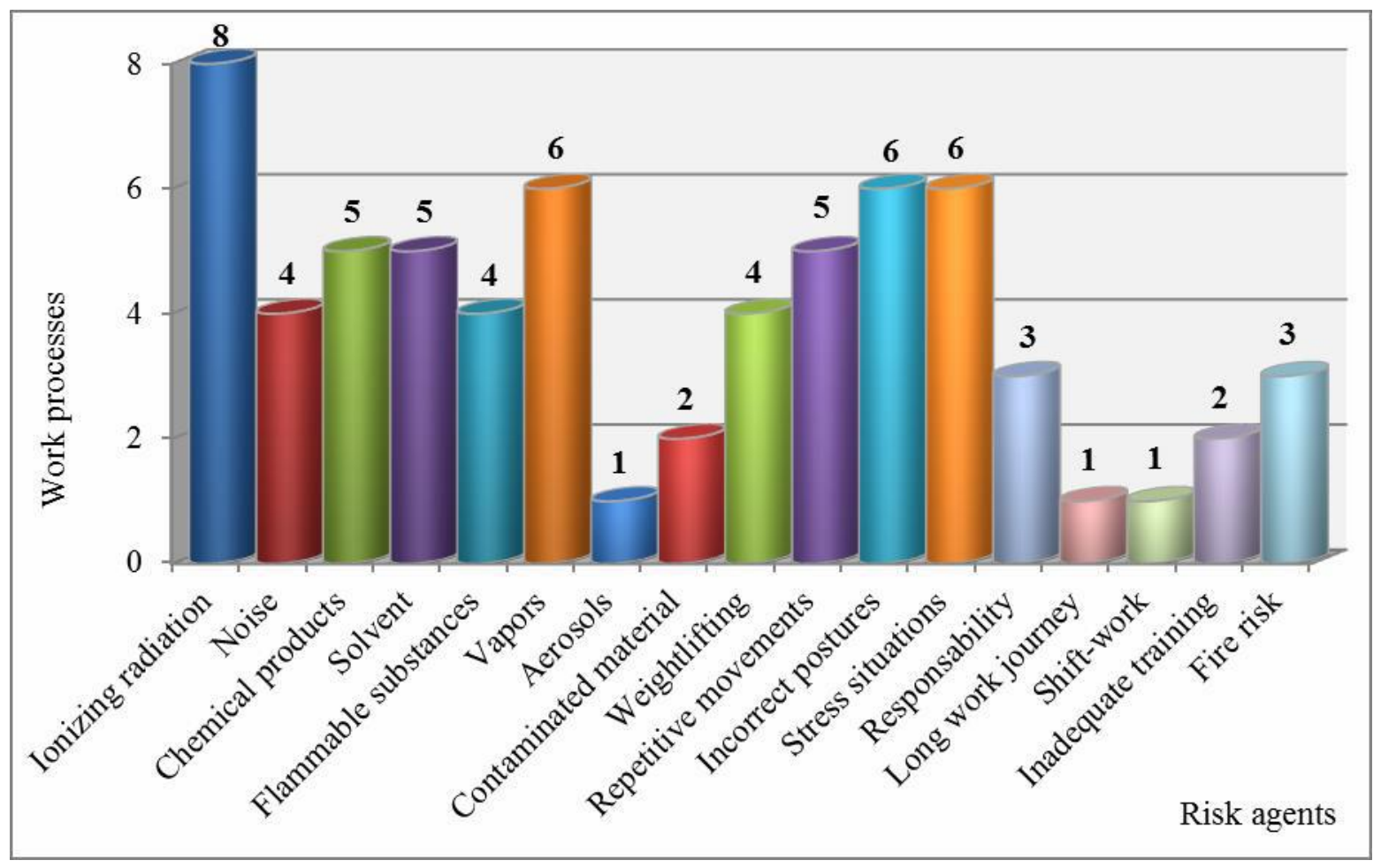


As observed among the work processes, ionizing radiation is the most common risk agent, followed by vapors agents, incorrect ergonomic postures at workplace and stress work-related situations. The workplace is a facility where exposures to ionizing radiation is inevitable, due to the influence of the radiation fields from the production of radioisotopes and radiopharmaceuticals products.

\subsubsection{Homogeneous exposure groups (HEGs)}

Workgroups presenting the same profile of exposure to a specific range of occupational risk agents are called homogeneous exposure groups (HEGs) Based on a systematic assessment of the subjective information collected during the basic characterization of the facility, a survey was carried out that enabled the determination of HEGs $[4,10]$.

Even though the facility has eight different work processes, two different profile groups are exposed to the same agent risks. The production of the primary radioisotopes group and the labeled compounds group are occupationally exposed to the same agent risks with similar frequency. Therefore, seven HEGs were considered for this study: Production (primary radioisotopes and labeled compounds), Lyophilized reagents (kits), Quality control, Quality Assurance, Research, Infrastructure and Radiation protection.

The only risk agent that could be quantified in this study was the ionizing radiation. Therefore, a statistical analysis was performed in order to estimate which of the identified risks agents (qualitative variables) could be associated with the occurrence of the occupational risks.

The qualitative dependent variable (occupational risk) has been characterized according to its relative frequency in each HEG.

Frequency analyses were performed for the occupational risks identified according to their type (physical risk, chemical, biological, ergonomic and accident), allowing to classify them into three main risk categories (Risk groups 1, 2 and 3). These three groups are exposed to similar workrelated risk types. Table 1 presents the analysis of frequencies performed by test equality of two proportions among the three risk groups. 
Table 1: Relative frequency distribution of the variable occupational risk among risk groups.

\begin{tabular}{|c|c|c|c|c|}
\hline Risk group & Occupational risk & $\begin{array}{c}\text { Number of } \\
\text { workers }\end{array}$ & Frequency $(\%)$ & p-value \\
\hline Risk 1 & $\begin{array}{l}\text { Physical, ergonomic and } \\
\text { accident }\end{array}$ & 29 & 28.4 & 0.020 \\
\hline Risk 2 & $\begin{array}{c}\text { Physical, chemical and } \\
\text { ergonomic }\end{array}$ & 45 & 44.1 & Ref. \\
\hline Risk 3 & $\begin{array}{l}\text { Physical, chemical, } \\
\text { biological, ergonomic } \\
\text { and accident }\end{array}$ & 28 & 27.5 & 0.013 \\
\hline
\end{tabular}

Note: $\mathrm{p}$-value considered significant statistically due to the adopted significance level $(\mathrm{p}<0.05)$.

Ref. (reference) considered the response prevalent level, or that shows the highest frequency and consequently the highest percentage. It is used only when the variable in study presents three or more response levels.

According to Table 1, the Risk group 2 is comprised by HEGs Production, Lyophilized reagents and Radiation protection, showed the highest frequency (44.1\%). The Risk group 1, comprised by workers pertaining to HEGs Quality assurance and infrastructure, shows a frequency similar to Risk group 3, which is from of HEGs of the Quality control and Research.

The relative frequencies of the qualitative variables could be analyzed based on the questionnaire results obtained through test equality of two proportions. The data analyzed showed that the sixteen qualitative variables were related to the worker tasks: radionuclides used in the radiopharmaceuticals production, mode of decay, physical aspects, chemicals products handling, temperature, presence of noise, presence and possibility of contact with ionizing radiation, handling and storage of dangerous chemical products, chemical contaminants dispersed in the air (vapor), bio- logical material handling, biological contaminants dispersed in the air (aerosols), probability of fires or explosions, inadequate lighting, physical workload (manual weightlifting and long work journey), mental workload (responsibility) and stressful situations.

Descriptive statistical analysis of the sociodemographic variables age, gender and education level were applied. ANOVA test and Yates correction test did not show statistically significant association ( $\mathrm{p}$-values>0.05) of these variables related to the occupational risk. The only variable that showed significant association with all three groups was the presence and 
possibility of contact with ionizing radiation $[4,11]$.

\subsection{Radiological Control}

The radiological control carried out between the years 2013 and 2014 at the radiopharmaceutical facility of IPEN showed to be effective, as confirmed by the routine occupational and environmental monitoring.

The results of area monitoring for external radiation, were carried out in 2013 with TL dosimeters totalizing 11 points. Of these, 5 points presented mean weekly values higher than the admissible maximum values of $400 \mu \mathrm{Sv}$ per week [1]. The higher dose rates were found out at points where the technetium-99m generator production was located and at the parking lot of the facility due to packages storage, for posterior shipment.

Actions of radiological protection were adopted: workers' instructions to avoid these radiation exposure points, improvements of infrastructure, such as shielding, and avoiding the accumulation of packages at Parking Lot.

The detected radionuclides were ${ }^{131} \mathrm{I},{ }^{125} \mathrm{I},{ }^{99 \mathrm{~m}} \mathrm{Tc}$ and ${ }^{99} \mathrm{Mo}$. The emissions of ${ }^{125} \mathrm{I}$ and ${ }^{99 \mathrm{~m}} \mathrm{Tc}$ resulted from leakages at the production cells. The ${ }^{99}$ Mo was detected in filter surface, indicating particulate material. The activity concentration values $\left(\mathrm{Bq} / \mathrm{m}^{3}\right)$ of these radionuclides, except of ${ }^{125}$ I, were above the admissible maximum values established by the Brazilian standard $[1,3]$.

In the monitoring period of 2013 the mean annual value of the background radiation at IPEN was $1.06 \mathrm{mSv}$ per year, confirming that there was no environmental impact due to the facility practices. Similar results were observed during 2014 monitoring procedures $[8,9]$.

The dose values found during the years 2013 and 2014 are in accordance with the limits established by the national regulatory. A reduction of $16 \%$ in the annual effective dose and in the collective dose was observed in 2014 when compared to year 2013 [1].

It was observed that continuous improvement of the area monitoring is necessary, with periodic inspections, mainly in the areas subject to contamination including the control of the IOE. In addition workers training were improved, as well as the fulfillment of the operational procedures. Moreover, several administrative procedures were adopted to prevent and to control the radiation exposure, which allowed a significant reduction of the dose and contamination. 


\section{CONCLUSIONS}

The radiation protection and the physical security teams of IPEN act in full compliance with the established operating procedures, according to the current international recommendations and Brazilian regulations.

Control measures such as engineering control, the use of individual protection equipment, monitoring of both area and personnel have been performed, and whenever necessary, new mechanisms for the mitigation of occupational risk for the welfare of the worker have been introduced. The analysis of the data obtained during the whole study showed information related to the processes, performed tasks, risk agents, occupational exposure limits, exposure assessment, health risk assessment and uncertainty assessment. The quantitative and qualitative approach carried out through the use of statistical methodology and subjective information allowed to find out the real conditions of the workplace, work processes and exposure of workers.

The main physical risk agent observed among them was the ionizing radiation, probably due to the daily handling of radioactive materials. Ionizing radiation and stressful situations expressed the highest frequencies due to the physical properties of the raw material used, and consequently the psychological pressure to dispatch short-lived radiopharmaceuticals rapidly.

Based on this study, our recommendation for future actions is that the homogeneous exposure groups and risk agents must be periodically analyzed and modified whenever necessary, taking into account that each new evaluation of the risk agents in the workplace should be carried out from the basic characterization phase. 


\section{REFERENCES}

1. CNEN, COMISSÃO NACIONAL DE ENERGIA NUCLEAR. Norma CNEN-NN-3.01, Diretrizes Básicas de Proteção radiológica, CNEN NN 3.01, 2014.

2. ICRP - INTERNATIONAL COMMISSION ON RADIOLOGICAL PROTECTION.

The 2007 Recommendations of the International Commission on Radiological Protection, Annals of the ICRP, Publication 103, Elsevier Ltd., 2007.

3. CNEN, COMISSÃO NACIONAL DE ENERGIA NUCLEAR. Posição Regulatória CNEN 3.01/004:2011 Restrição de dose, níveis de referência ocupacionais e classificação de áreas, Available at: <http://appasp.cnen.gov.br/seguranca/normas/pdf/pr301_04.pdf.

4. ALVES, A. S. Estudo dos agentes de risco ocupacional e seus prováveis agravos à saúde humana, Dissertação (Mestrado) - Instituto de Pesquisas Energéticas e Nucleares, São Paulo.

5. CARNEIRO, J.C.G.G., ALVES, A.S., RODRIGUES, D.L., LEVY, D.S., SORDI, G.M.A.A. Basic characterization of a radioactive facility and evaluation of occupational risk. In: 14th INTERNATIONAL CONGRESS OF THE INTERNATIONAL RADIATION PROTECTION ASSOCIATION- IRPA, Cape Town, 2016.

6. IBM SPSS SOFTWARE. SPSS Statistics Base 17.0 User's Guide. http://www.jou.ufl.edu/archive/researchlab/SPSS-Statistcs-Base-Users-Guide-17.0.pdf. ～(Last accessed: February, 2016).

7. SPIEGEL. M. R. Estatística, $3^{a}$ ed. Makron Books, São Paulo, 1993.

8. PMRA, Programa de Monitoração radiológica Ambiental, IPEN/SP. São Paulo, htpp:/intranet.ipen.br Sistema de Gestão Integrada do IPEN 2014. 
9. CARNEIRO, J.C.G.G., SANCHES, M.P., RODRIGUES, D.L.,CAMPOS, D., NOGUEI- RA, P.R.,DAMATTO, S.R., PECEQUILO, B.R,S. Assessment of the radiological control at the IPEN Radioisotope Production Facility. In: BJRS-Brazilian Journal of Radiation Sciences, v.3, n.2, p. $1-10,2015$.

10. MENDES. R. Patologia do Trabalho. Ed. Atheneu $2^{\circ}$ edição v. 1. São Paulo, 2007.

11. ALVES, A. S., CAMPOS, D., CARNEIRO, J. C. G. G. Results of the study of variables related to tasks of workers of a radioactive facility. In: 2015 INTERNATIONAL NU- CLEAR ATLANTIC CONFERENCE, São Paulo, 2015. 